\title{
Immunohistochemical Localization of Cystic Fibrosis Transmembrane Conductance Regulator in Human Fetal Airway and Digestive Mucosa
}

\author{
DOMINIQUE GAILLARD, SANDRINE RUOCCO, AUDE LALLEMAND, WILFRIED \\ DALEMANS, JOCELYNE HINNRASKY, AND EDITH PUCHELLE
}

INSERM U 314, Université de Reims, 51092 Reims Cédex, France /D.G., S.R., A.L., J.H.,

E.P.I, and Transgene, 67082 Strasbourg Cédex, France /W.D.I

\section{ABSTRACT}

\begin{abstract}
The cellular distribution of the cystic fibrosis transmembrane conductance regulator (CFTR) in human fetal digestive and respiratory mucosa has been studied by immunohistochemistry. The streptavidin-biotin immunoperoxidase method was applied to paraffin-embedded specimens collected from normal fetuses ranging from 7 to $39 \mathrm{wk}$ of gestation. By the 7th wk, CFTR protein was strongly detected in the yolk sack; in contrast, the staining was weak in the undifferentiated epithelium of the intestine and the airways. At $12 \mathrm{wk}$, the intestine showed strongly and diffusely stained enterocytes and a basal cytoplasmic reactivity in the first secretory cells. During development, only slight changes could be detected in the digestive epithelial distribution of CFTR. In the airways, the CFTR distribution followed the cephalocaudal maturation. In the tracheal ciliated cells, the CFTR protein was diffusely detected in the cytoplasm as early as $7 \mathrm{wk}$. After $24-25 \mathrm{wk}$, CFTR was
\end{abstract}

$\mathrm{CF}$ results from mutations in the gene coding for the CFTR, a protein that plays a fundamental role in electrolyte and water transport. Recent studies have demonstrated that the CFTR is a cytoplasmic protein with an intramembrane domain $(1,2)$. It is considered a chloride channel (3) whose kinetics and subcellular localization are altered in CF (4). Immunocytochemical analysis of the CFTR protein distribution showed its presence in the human adult epithelial cells lining the sweat ducts, small pancreatic ducts, intestinal crypts, and kidney tubules (5-7) and also in normal and CF airway epithelia (8).

Progressive chronic lung disease, as well as pancreatic and intestinal dysfunction, the main clinical features of $\mathrm{CF}$, usually occur during early childhood. Only $16 \%$ of the affected neonates have a greatly increased viscosity

Received June 29, 1993: accepted February 24, 1994

Correspondence: Professor Dominique Gaillard, INSERM U 314, CHR Maison Blanche, 45, rue Cognacq Jay, 51092 REIMS Cédex. France.

Supported hy a grant from AFLM (Association Française de Lutte contre ba Mucoviscidose). localized at the apical domain of the ciliated cells and was also present in the collecting ducts and in the glands of the airways, predominantly in the periphery of the acini. Our data suggest that the CFTR is present as early as $7 \mathrm{wk}$ during organogenesis and probably plays an important role during fetal life. There is an evolution in the CFTR distribution during airway development, whereas, in the intestine, CFTR is highly expressed through the epithelium as early as $12 \mathrm{wk}$ and keeps the same distribution until birth. (Pediatr Res 36: 137-143, 1994)

\author{
Abbreviations \\ CFTR, cystic fibrosis transmembrane conductance \\ regulator \\ CF, cystic fibrosis \\ GA, gestational age
}

of the meconium, leading to meconium ileus, which may or may not be associated with meconium peritonitis (9). Curiously, at midgestation, dilated loops of the bowel can be detected in $90 \%$ of the aborted and affected fetuses (10). Such a spontaneous disappearance of most of the meconium ileus in the affected neonates could be either associated with a maturation and a modification in the distribution of the CFTR protein in epithelial cells throughout the different periods of gestation or the result of another unknown mechanism. The expression of CFTR mRNA has been reported in human fetal epithelial cells of the lung, pancreas, and intestine (11-13). Although there is an epithelium-specific expression of the CF gene in human adult tissue (5), the precise localization of the CFTR protein in the normal human fetus at different ages of gestation has not yet been fully described. The cellular differentiation and cellular phenotype are factors that regulate CFTR expression (14). We were therefore interested in the localization of the CFTR protein during normal fetal development and analyzed its cellular distri- 
bution during maturation. In the present study, we used a monoclonal anti-CFTR antibody to analyze the cellular localization of CFTR in the respiratory and digestive mucosa of human embryos and fetuses.

\section{METHODS}

Fetal tissue material. Eighteen embryos and fetuses, ranging from 7 to 39 wk GA (menstrual age) were obtained from spontaneous abortions or medical inductions. The age distribution is indicated in Table 1. All these fetuses were well preserved; none showed any digestive or respiratory abnormality or infection. They were not associated with either polyhydramnios or oligohydramnios. Different tissue specimens were collected from the airway (trachea, bronchi, and distal lung) and from the esophagus, stomach, and small and large intestine. Tissue samples were immediately fixed in $15 \%$ formalin and embedded in paraffin. In two fetuses, at 10 and 25 wk GA, part of the respiratory material was immediately frozen in liquid nitrogen and part of it was fixed in $15 \%$ formalin.

Anti-CFTR antibody. An MAb, MATG 1061, was raised against a synthetic peptide corresponding to CFTR amino acid position 503 to 515 without the residue 508, thus corresponding to the $\triangle$ Phe 508 epitope in the CFTRNBF1 domain. The specificity of MATG 1061 toward normal CFTR and $\Delta F$ 508-CFTR was assessed by immunoprecipitation and immunodetection of fibroblasts expressing recombinant CFTR, as previously described (8).

Immunohistochemistry. Paraffin sections were cut (3 $\mu \mathrm{m})$, mounted on gelatin-coated slides, and dried overnight at $50^{\circ} \mathrm{C}$. The tissue sections were then deparaffinized with xylene and rehydrated first in graded ethanol baths and then in distilled water and PBS, pH 7.2. Immunohistochemical staining was carried out using the streptavidin-biotin complex technique. The sections were incubated in a hydrogen peroxide bath for $5 \mathrm{~min}$ at room temperature to remove endogenous peroxidase activity and rinsed in PBS. A blocking reagent $(6 \%$ goat serum) was added for $5 \mathrm{~min}$. The slides were then rinsed twice with PBS. The tissue sections were incubated with MATG 1061 at a dilution of 1:400 in PBS at room temperature for $10 \mathrm{~min}$. After two rinses, the sections were

Table 1. Immunolocalization of CFTR protein in human fetal intestinal and lange conducting airway mucosa*

\begin{tabular}{lcccc}
\hline & \multicolumn{4}{c}{ Gestational age (wk) } \\
\cline { 2 - 5 } & $7-11$ & $12-15$ & $16-24$ & $25-39$ \\
\hline $\begin{array}{l}\text { Number of fetuses } \\
\text { Intestine }\end{array}$ & 4 & 3 & 5 & 6 \\
$\begin{array}{l}\text { Surface epithelium } \\
\text { Glands }\end{array}$ & $\mathrm{D}++$ & $\mathrm{D}++$ & $\mathrm{D}++$ & $\mathrm{D}++$ \\
$\begin{array}{l}\text { Large airways } \\
\text { Surface epithelium } \\
\text { Glands }\end{array}$ & $\mathrm{D}++$ & $\mathrm{D}++$ & $\mathrm{D}+$ & $\mathrm{D}+$ \\
& $\mathrm{D}+$ & $\mathrm{D}++$ & $\mathrm{D}++$ & $\mathrm{A}++$ \\
& - & $\mathrm{D}+$ & $\mathrm{D}+$ & $\mathrm{D}+$ \\
\hline
\end{tabular}

* D, Diffuse cytoplasmic immunoreactivity; A, apical domain immunoreactivity; ++ , intense immunoreactivity; + , weak immunoreactivity; - , glands are not yet developed. incubated for an additional $10 \mathrm{~min}$ with an anti-mouse IgG biotinylated antibody and then for $10 \mathrm{~min}$ in labeled streptavidin. The sections were exposed to chromogen substrate solution (3\% 3-amino 9-ethyl carbazole) for an additional $10 \mathrm{~min}$ (Dako LSAB kit, DAKO S.A., Trappes, France). After rinsing, the sections were counterstained with hematoxylin, dehydrated, and topped with a coverslip. Negative controls were performed 1 ) by omitting the primary antibody incubations, 2) by using nonimmune mouse serum, and 3) by using the purified $\operatorname{IgG} 2 \kappa$ fraction instead of specific anti-CFTR antibodies. Specificity of the MATG 1061 was confirmed by showing that the CFTR tissue labeling was blocked by preincubation of the MATG with the corresponding peptide immunogen.

In two cases, fetal tracheal tissue (11 and 25 wk GA) was frozen in liquid nitrogen. The frozen sections were subsequently rinsed in PBS and incubated for $60 \mathrm{~min}$ with MATG 1061 at a dilution of 1:400. After two rinses in PBS, the sections were incubated for $45 \mathrm{~min}$ with antimouse IgG biotinylated complex at a dilution of $1: 50$ in PBS and then incubated for $30 \mathrm{~min}$ with FITC-avidin (Amersham, Les Ulis, France). All FITC images were collected with a Zeiss Axiophot light microscope.

\section{RESULTS}

In the sections of human embryos of $7 \mathrm{wk}$ GA, the highest intensity of anti-MATG 1061 immunostaining was present in the endoderm of the yolk sack (Fig. 1). A delicate weak and diffuse immunostaining was seen in the undifferentiated columnar epithelium around the small lumen of the airways (Fig. 2) and intestine (not shown). In the mesenchyme and the endothelial cells of the capillaries, no CFTR labeling was detected.

During the next 4 wk of development, the wall of the trachea and first bronchi became structured, showing cartilage and muscle fibers; the epithelium, however, was still poorly differentiated without any ciliated or secretory cells. Peroxidase and FITC-avidin staining was diffusely present in the cytoplasm of the columnar epithelial cells, in the fibroblasts surrounding the cartilage rings, and around the nuclei of the chondroblasts (Fig. 3). The

Figure 1. Immunolocalization of CFTR in the yolk sack at 7 wk GA. High immunoreactivity in the cells of the endoderm (arrow). Bar $=50 \mu \mathrm{m}$.

Figure 2. Immunolocalization of CFTR in human trachea at 7 wk GA (same section as Fig. 1). $A$, Weak and diffuse labeling of CFTR in the columnar cells lining the lumen. $B$, Negative control. Bar $=50 \mu \mathrm{m}$.

Figure 3. Immunolocalization of CFTR in trachea at 11 wk GA. The epithelium shows diffuse positive immunoreactivity to CFTR using both techniques ( $A$, peroxidase; $B$, FITC). Mesenchymal cells surrounding the cartilage ring as well as chondroblasts are immunostained $(A)$. Bar $=50 \mu \mathrm{m}$.

Figure 4. Immunolocalization of CFTR in the small intestinal and colonic mucosa at 11 wk GA. There was high immunostaining in enterocytes lining the villi of the small intestine, whereas the crypts were negative. $A$, The labeling is diffuse in the undifferentiated colonic epithelium. $B$, Negative control. Bar $=50 \mu \mathrm{m}$. 

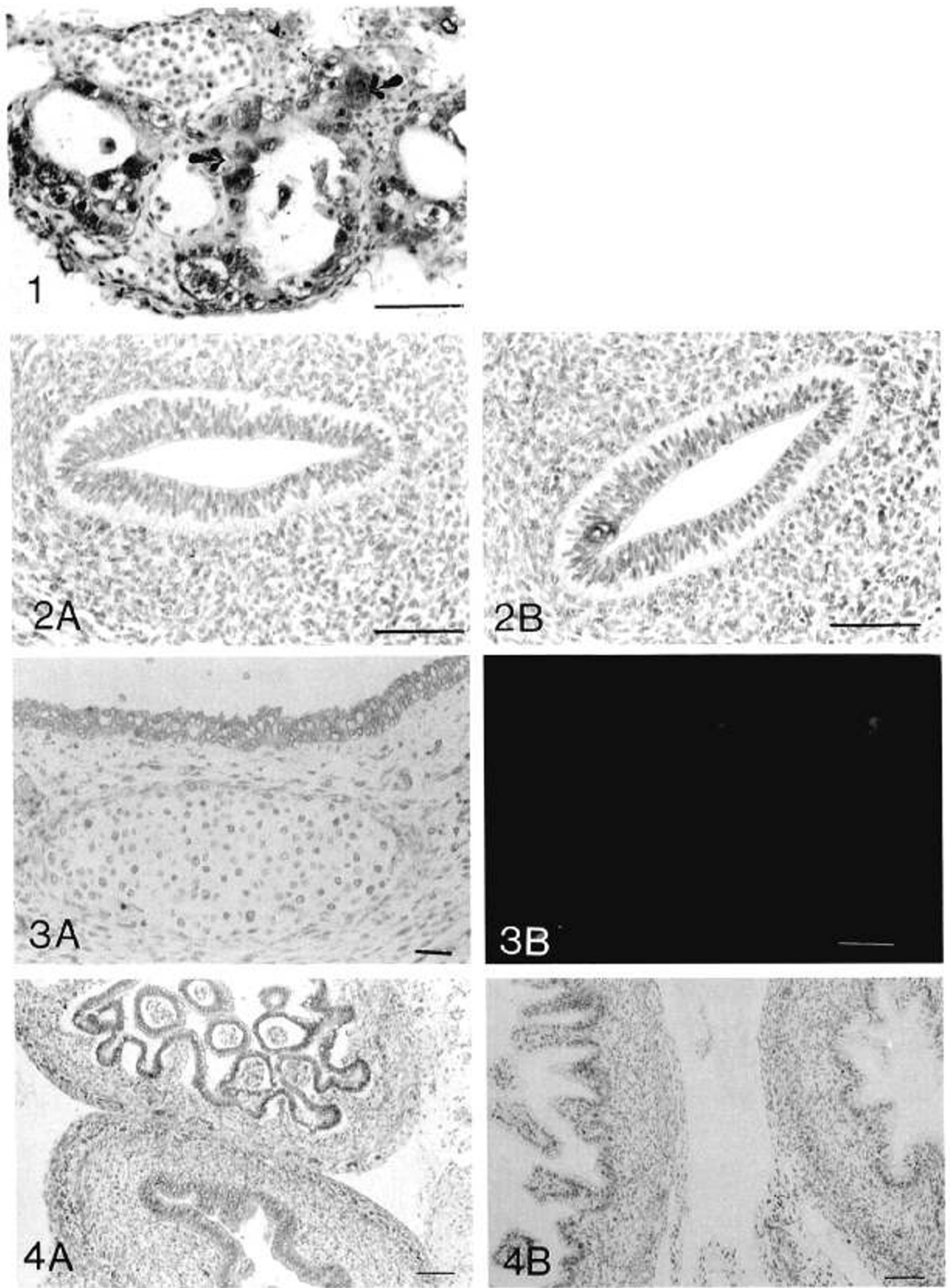
digestive epithelium differentiated a little earlier than the respiratory epithelium, and the intensity of the immunostaining was stronger in the enterocytes lining the lumen than in the surface tracheal epithelium (Fig. 4, Table 1).

Between 12 and 15 wk GA, the epithelia became more differentiated, following a progressive craniocaudal maturation. The tracheal epithelium contained CFTR immunostained ciliated and undifferentiated cells. Secretory cells were numerous but showed no CFTR reactivity in their granules. The first glandular buds and ducts of the trachea and the lower epithelial airways were stained. The esophageal epithelium was lined with ciliated cells that showed the same characteristics as respiratory epithelial cells but with an earlier maturation. In the stomach, the clear surface epithelial cells and the glands were immunostained. The enterocytes lining the primitive intestinal villi and the colonic mucosa showed the same positive immunostaining.

From 16 to $24 \mathrm{wk}$ GA, no significant changes were detected in the immunoreactivity of the surface epithelium of the trachea and of the major bronchi (Fig. 5). The immunoreactivity decreased markedly from small bronchi to the distal respiratory tubules (not shown). During this period of gestation, the glands consisted only of mucous tubules with pale polygonal cells and a few columnar positively stained cells. Endothelial cells lining large vessels or capillaries did not show any traces of CFTR during fetal development. The gastric epithelium and a few parietal cells in the glands were immunostained. In the small intestine, there was a high level of CFTR staining in the enterocytes lining the villi (Fig. 6). The reactivity was weaker in the crypts. The goblet cells of the small intestine, like those in the colon or rectum, showed a basal cytoplasmic labeling, but the mucous granules were unstained.

Over the GA of $25 \mathrm{wk}$, the epithelium of the large conducting airways was mature and exhibited a different immunohistochemical distribution of CFTR compared with that observed in earlier gestation (Fig. 7). On both frozen and paraffin sections, the labeling was mainly localized in the apical domain of the tracheal and bronchial ciliated cells. No reactivity was detected in the surface mucous secretory cells. The immunoreactivity was diffused in the collecting ducts and irregular in the glands, where the positivity seemed to predominate in the serous acini localized at the distal end of the mucous tubules. In the lower bronchi, the ciliated or undifferentiated cells exhibited significant immunopositivity throughout their whole cytoplasm. The alveoli around these small bronchi showed no or very slight immunoreactivity. No significant change could be detected in the different parts of the intestinal epithelia (Fig. 8).

\section{DISCUSSION}

In the present study, an antibody raised against an epitope of the CFTR protein was used to identify the localization of this protein during early human develop- ment. The specificity of this antibody has previously been demonstrated (8). Recombinant CFTR protein was specifically immunoprecipitated by MATG 1061 as a $145-\mathrm{kD}$ protein that has the predicted molecular mass of nonglycosylated CFTR and could represent an immature protein $(4,15)$. The fully mature CFTR, which has an apparent molecular mass of $170 \mathrm{kD}$, was also recognized by the antibody. In the present study, the immunoreactivity could thus demonstrate either the immature or the mature CFTR. The results obtained with frozen sections and paraffin sections were similar.

The immunohistochemical study showed an early expression of CFTR in embryonic cells, and the protein was detected in undifferentiated endodermal epithelial cells. Immunoreactivity was first detected in the yolk sack as early as $7 \mathrm{wk}$. This observation suggests that CFTR may be involved in the kinetics of electrolyte and water exchange through both the extraembryonic membranes and embryonic tissue.

In human embryos, the immunoreactivity of the endodermal derivatives was early and intense. These results support those of Bremer et al. (16), who reported that CFTR mRNA was present at high levels in human epithelial cells in the jejunum and the liver. Recently, CFTR transcripts were localized in the crypts of human fetal intestine. A high expression was detected in the progenitor cell area, with a decreasing gradient along the cryptvillous axis and no detectable expression in the luminal half of the villi $(17,18)$. The differences between the localization of CFTR mRNA and the CFTR protein in the cells along the villi could be the result of a possible regulation of CFTR expression during the differentiation (19) and migration process of enterocytes. Clinical observations suggest that in fetal intestinal function CFTR probably plays a major role in the elaboration of meconium. At midgestation, $90 \%$ of the fetuses affected with CF present a meconium ileus that results from dehydration of intestinal mucus (10). Additional studies of CFTR function in embryonic and fetal intestine would be useful to understand the nearly constant ileus associated with $\mathrm{CF}$ at midgestation. CFTR could be implicated in none-

Figure 5. Immunolocalization of CFTR in the trachea at 19 wk GA. The surface epithelium shows positive ciliated and nondifferentiated columnar cells. $A$, The cells lining the glandular ducts are immunostained, whereas the mucous granules are negative. $B$, Negative control. Bar $=50 \mu \mathrm{m}$.

Figure 6. Immunolocalization of CFTR in the small intestine at 23 wk GA. $A$, The labeling is higher in the enterocytes lining the villi than in the crypts. $B$, Negative control. Bar $=30 \mu \mathrm{m}$.

Figure 7. Immunolocalization of CFTR in the fetal trachea at 25 wk GA using the FITC technique $(A)$ and at 39 wk using the peroxidase technique $(B)$. In both cases, the reactivity predominates in the apical domain of ciliated cells. The cells lining the collecting ducts and the periphery of the glands are also immunostained. Bar $=50 \mu \mathrm{m}$.

Figure 8. Immunolocalization of CFTR in the rectum at $28 \mathrm{wk}$ GA. $A$, The immunoreactivity of CFTR is localized in the goblet cells (outside of the secretory granules). $B$, Negative control. Bar equals $=50 \mu \mathrm{m}$. 

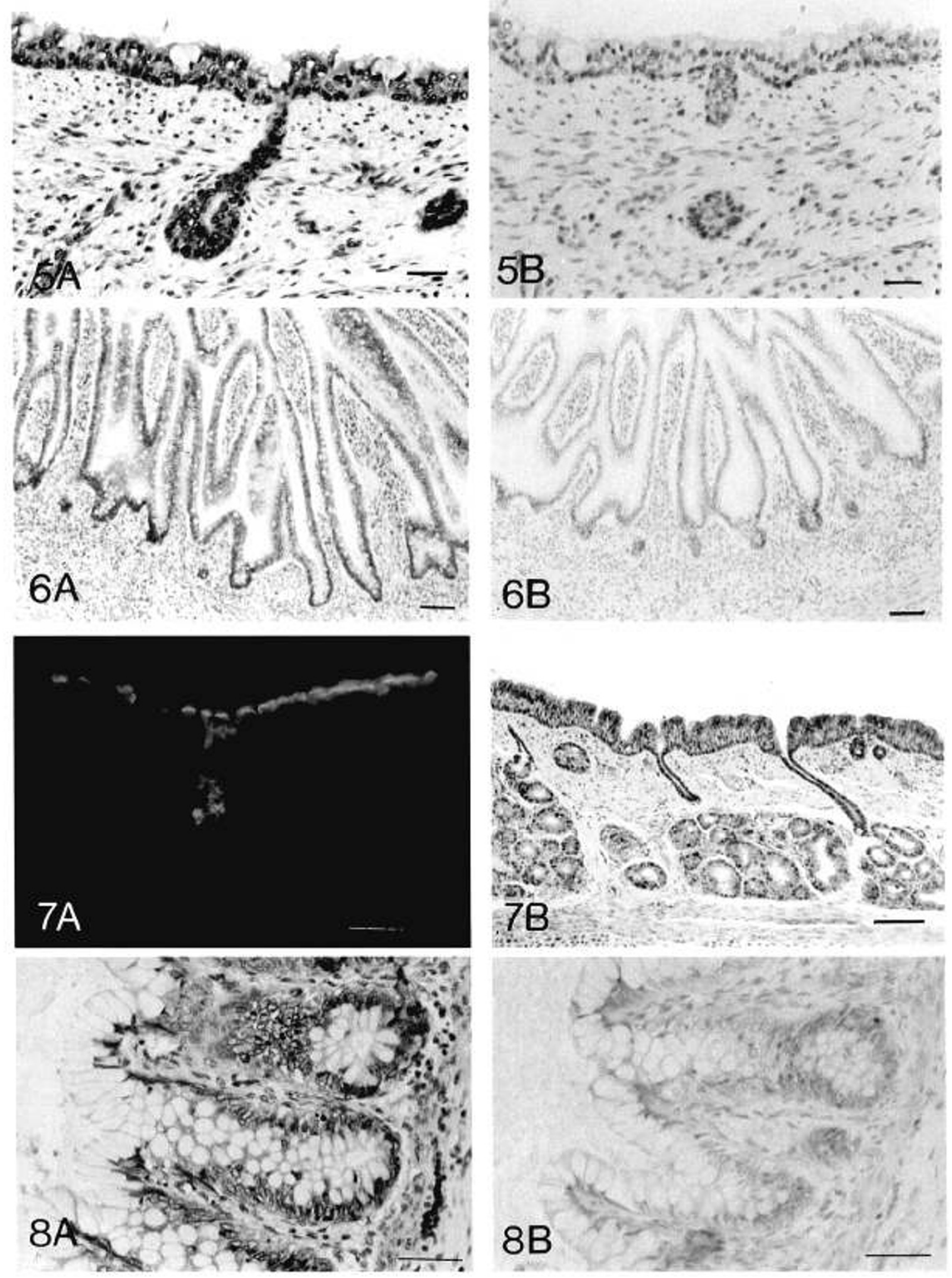
pithelial cells such as muscle or enteric nervous plexus in the intestinal wall. Recently, CFTR transcripts were detected in a variety of secretory and nonsecretory organs, such as brain and heart, in fetal rabbits (20).

The localization of CFTR and the intensity of the immunoreactivity in the airways were different throughout the successive periods of development and differed in the various parts of the airways. We previously described four stages of maturation in the fetal human tracheal epithelium (21). During the first stage, before $12 \mathrm{wk}$, the epithelium was undifferentiated and CFTR immunodetection was very weak compared with that of the intestine. Later, during the second stage of maturation of the respiratory epithelium (from 12 to 19-20 wk), the number of ciliated and secretory cells increased, and the cellular immunoreactivity was intense and diffuse. That could be an argument in favor of the role of CFTR in secretory processes, inasmuch as surface secretory cells are numerous at this time of development, and CFTR can also function within intracellular membranes. Both endocytosis and exocytosis are regulated by cAMP in epithelial cells that express CFTR (22). During the third stage, the number of secretory cells decreased, and the increasing number of ciliated cells remained diffusely immunostained. During the last stage (GA of $25 \mathrm{wk}$ and more) the tracheal epithelium was mature and the distribution of CFTR was limited to the apical domain of ciliated cells with a high level of staining. This shift of staining from cytoplasmic to apical domain is not likely to be associated with the development of tight junctions or terminal webs, which have been shown to be present very early along immature epithelia (21). It is of interest to note that in the cryofixed sections at 25 wk GA the CFTR staining pattern was similar to that observed in adult respiratory tissue (8). During this period, CFTR also became widespread in the glands. Our results were thus similar to those reported for adult tracheal specimens $(23,24)$.

In situ hybridization techniques showed CFTR mRNA in human fetal epithelial cells of the lung $(17,18)$ and indicated that a decreasing gradient of CFTR mRNA expression was present from the proximal to the distal respiratory epithelium. We also observed a decreasing gradient of CFTR protein labeling from the trachea and bronchi to the lowest pulmonary ducts during development (data not shown). In the young fetal rabbit, using an anti-R-IgG antibody, McGrath et al. (20) recently reported that CFTR protein was not polarized to one domain of the epithelial cells, whereas later in the terminal sac period of fetal lung development, CFTR was much more prominent on the apical pole of the bronchiolar epithelium. Our present results are in agreement with the results of McGrath et al. (20). During human fetal lung development, the distribution of CFTR is first nonpolarized and shifts to a more prominent apical staining of the ciliated cells. This apical distribution is similar to that observed in human adult surface epithelium (8). Surprisingly, Tizzano et al. (17) detected no CFTR mRNA in the fetal submucosal glands even during the last stages of gestation. McCray et al. (13) recently studied the cAMPmediated fluid secretion in the lung explants of normal human fetuses and showed a defect in secretion in the explants of CF fetuses. In our study, the absence of only weak CFTR staining in pneumocytes suggests that most of the pulmonary CFTR-dependent chloride secretion in the amniotic fluid is caused by airway surface and glandular epithelial cells.

In summary, we have shown that the CFTR protein can be detected from very early (7 wk) human development in epithelial derivatives of the endoderm. Along the different periods of gestation, no significant change could be detected in the distribution of CFTR in the intestinal epithelia, whereas a shift from cytoplasmic to apical staining was observed in the ciliated cells of the airways.

Acknowledgments. The authors thank G. Himbert, N. Lalun, M. Fé, I. Rapace, and A. Guidez for their excellent technical assistance and A. Quiqueret and C. Juppin for typing the manuscript.

\section{REFERENCES}

1. Kartner N, Augustinas O, Jensen TJ, Naismith AL, Riordan JR 1992 Mislocalization of DF508 in cystic fibrosis sweat gland. Nature Genet 1:321-327

2. Riordan JR 1993 The cystic fibrosis transmembrane conductance regulator. Annu Rev Physiol 55:609-630

3. Anderson MP, Rich DP, Gregory RJ, Smith AE, Welsh MJ 1991 Generation of cAMP-activated chloride currents by expression of CFTR. Science 251:670-682

4. Dalemans W, Barbry P, Champigny G, Jallat S, Dott K, Dreyer D, Crystal RG, Pavirani A, Lecocq J, Ladzunski M 1991 Altered chloride ion channel kinetics associated with the F508 cystic fibrosis mutation. Nature 354:526-528

5. Crawford I, Maloney PC, Zeitlin PL, Guggino WB, Hyde SC, Turley H, Gatter KC, Harris A, Higgins CF 1991 Immunocytochemical localization of the cystic fibrosis gene product CFTR. Proc Natl Acad Sci USA 88:92629266

6. Hoogeveen AT, Keulemans J, Willemsen R, Scholte BJ, Bijman J, Edixhoven MJ, Dejonge HR, Galjaard H 1991 Immunological localization of cystic fibrosis candidate gene products. Exp Cell Res 193:435-437

7. Marino CR, Matovcik LM, Gorelick FS, Cohn JA 1991 Localization of the cystic fibrosis transmembrane conductance regulator in pancreas. J Clin Invest 88:712-716

8. Puchelle E, Gaillard D, Ploton D, Hinnrasky J, Fuchey C, Boutterin MC, Jacquot J, Dreyer D, Pavirani A, Dalemans W 1992 Differential localization of the cystic fibrosis transmembrane conductance regulator in normal and cystic fibrosis airway epithelium. Am J Respir Cell Mol Biol 7:485-491

9. FitzSimmons SC 1993 The changing epidemiology of cystic fibrosis. J Pediatr 122:1-9

10. Muller F, Aubry MC, Gasser B, Duchatel F, Boue J, Boue A 1985 Prenatal diagnosis of cystic fibrosis. II. Meconium ileus in affected fetuses. Prenat Diagn 5:109-117

11. Harris A, Chalkley G, Goodman S, Coleman L 1991 Expression of the cystic fibrosis gene in human development. Development 113:305-310

12. McCray Jr PB, Wohlford-Lenane CL, Snyder JM 1992 Localization of cystic fibrosis transmembrane conductance regulator $m R N A$ in human fetal lung tissue by in situ hybridization. J Clin Invest 90:619-625

13. McCray Jr PB, Reenstra WW, Louie E, Johnson J, Bettencourt JD, Bastacky J 1992 Expression of CFTR and presence of cAMP-mediated fluid secretion in human fetal lung. Am J Physiol 262:L472-L481

14. Montrose-Rafizadeh C, Guggino WB, Montrose MH 1991 Cellular differentiation regulates expression of $\mathrm{Cl}$-transport and cystic fibrosis transmembrane conductance regulator mRNA in human intestinal cells. J Biol Chem 266:4495-4499

15. Gregory RJ, Cheng SH, Rich DP, Marshall J, Paul S, Hehir K, Ostedgaard L, Klinger KW, Welsh MJ, Smith AE 1990 Expression and characterisation of the cystic fibrosis transmembrane conductance regulator. Nature 347:382-386

16. Bremer S, Hoof T, Wilke M, Busche R, Scholte B, Riordan JR, Maass G, Tummler B 1992 Quantitative expression patterns of multidrug-resistance P-glycoprotein (MDR1) and differentially spliced cystic-fibrosis transmembrane-conductance regulator mRNA transcripts in human epithelia. Eur $J$ Biochem 206:137-149

17. Tizzano EF, Chitayat D, Buchwald M 1993 Cell-specific localization of CFTR mRNA shows developmentally regulated expression in human fetal tissues. Hum Mol Genet 3:219-224 
18. Trezise AEO, Chambers JA, Wardle CJ, Gould S, Harris A 1993 Expression of the cystic fibrosis gene in human fotal tissues. Hum Mol Genet 3:21,3-218

19. Sood R, Bear C, Auerbach W, Reyes E, Jensen T, Kartner N, Riordan JR, Buchwald M 1992 Regulation of CFTR expression and function during differentiation of intestinal epithelial cells. EMBO J 11:2487-2494

20. McGrath SA, Basu A, Zeitllin P 1993 Cystic fibrosis gene and protein expression during fetal lung development. Am J Respir Cell Mol Biol 8:201-208

21. Gaillard DA, Lallemand AV, Petit AF, Puchelle ES 1989 ln vivo ciliogenesis in human fetal tracheal epithelium. Am J Anat 185:415-428
22. Bradbury NA, Jilling T, Berta G, Sorscher EJ, Bridges RJ, Kirk KL 1992 Regulation of plasma membrane recycling by (FTR. Science 256:530-532

23. Engelhardt JF, Yankaskas JR, Ernst S, Yang Y, Marino CR, Boucher RC, Cohn JA, Wilson JM 1992 Submucosal glands are the predominant site of CFTR expression in the human bronchus. Nature Genet 2:24()-247

24. Jacquot J, Puchelle E, Hinnrasky J, Fuchey C, Bettinger $C$, Spilmont $C$ Bonnet N, Dieterle A, Dreyer D, Pavirani A, Dalemans W 1993 Localization of the cystic fibrosis transmembrane conductance regulator in airway secretory glands. Eur Respir J 6:169-176 